\title{
Temporal artery thermometer use in the prehospital setting
}

\author{
Erica Carleton, BA, MSc*; Brenda Fry, ACPt; Ashlee Mulligan, BA, MSc*; Ali Bell, MA, MSc*; \\ Cory Brossart, ACP, BHSc ${ }^{\dagger}$
}

\section{ABSTRACT}

Objectives: Prehospital vital signs are an important and required component of patient assessment. We compared the temporal artery thermometer (TAT) to the digital thermometer currently used in our emergency medical service (EMS) system and then to the digital thermometer used in the emergency department. The primary objective of this study was to assess the usefulness of the TAT in the prehospital setting. Other outcomes of interest included whether extraneous factors or cold ambient temperatures affected the TAT readings and paramedic satisfaction with the TAT.

Methods: This was a prospective, observational study. Patient temperature was taken by EMS personnel with both the digital thermometer and the TAT, and a chart review was conducted on a sample of these patients to compare the TAT to the emergency department digital thermometer.

Results: A total of 818 patients had their temperatures taken with both thermometers in the prehospital setting. The relationship between the TAT and digital thermometer measurement was positive and moderate; however, there was poor agreement between the two devices. Sixty-nine charts were reviewed, and a positive correlation was found between the TAT and the emergency department digital thermometer, with good agreement between the two devices. No extraneous factors were found to have a noticeable effect on the temperature measurements; the TAT performed well in cold weather, and the EMS personnel reported it to be easy to use.

Conclusion: The TAT appears to be a suitable alternative to digital thermometers currently used in many EMS systems. The paramedics involved in this study liked the TAT better than the in-ambulance digital thermometer and believed it to be more accurate. Further research on this topic is required.

\section{RÉSUMÉ}

Objectifs: Les signes vitaux préhospitaliers sont un élément important et nécessaire à l'évaluation des patients. Nous avons d'abord comparé le thermomètre de l'artère temporale (TAT) au thermomètre numérique actuellement utilisé dans notre système de service médical d'urgence (SMU), puis au thermomètre numérique utilisé au service d'urgence. Le principal objectif de cette étude était de mesurer I'utilité du TAT en milieu préhospitalier. D'autres objectifs étaient de déterminer si des facteurs externes ou des températures ambiantes froides affectaient les lectures du TAT et de connaître le taux de satisfaction des ambulanciers par rapport à celui-ci.

Méthodes: Il s'agit d'une étude prospective et observationnelle. La température des patients a été prise avec le thermomètre numérique et le TAT par le personnel du $\mathrm{SMU}$; on a ensuite examiné les dossiers d'un échantillon de ces patients pour comparer les lectures du TAT avec celles du thermomètre numérique du service d'urgence.

Résultats: La température d'un total de 818 patients a été prise avec les deux thermomètres en milieu préhospitalier. On a observé une relation positive et modérée entre les mesures du TAT et celles du thermomètre numérique; toutefois, les deux dispositifs ont montré peu de concordance. On a ensuite examiné 69 dossiers, et trouvé une corrélation positive entre les mesures obtenues avec le TAT et le thermomètre numérique du service d'urgence, avec une bonne concordance entre les deux dispositifs. II n'a pas été montré que des facteurs externes avaient un effet notable sur les mesures de température; le TAT a eu de bons résultats par temps froid, et le personnel du SMU a indiqué qu'il était facile d'utilisation.

Conclusion: Le TAT semble être une solution de rechange convenable pour le thermomètre numérique actuellement utilisé dans plusieurs systèmes de SMU. Les ambulanciers ayant participé à cette étude ont préféré le TAT au thermomètre numérique de l'ambulance et le jugent plus précis. II

From the * Regina Qu'Appelle Health Region - Research and Performance Support, Regina, SK; †Regina Qu'Appelle Health Region - Emergency Medical Services.

Correspondence to: Erica Carleton, Regina Qu'Appelle Health Region - Research and Performance Support, ROHR Wascana Rehabilitation Centre, 2180-23rd Avenue, Regina, SK S4S 0A5.

This article has been peer reviewed.

(C) Canadian Association of Emergency Physicians 
sera nécessaire d'effectuer des recherches plus poussées sur ce sujet.
Keywords: ambulance, emergency medical service, prehospital, temporal artery thermometer, thermometers
Prehospital vital signs are extremely important when assessing a patient's condition and are a basic life support requirement in all emergency medical service (EMS) systems. ${ }^{1}$ Temperature measurement has considerable clinical impact because it provides important data required to guide the delivery of care, ${ }^{2,3}$ such as using therapeutic hypothermia for cardiac arrest patients or monitoring patients with accidental hypothermia. ${ }^{4}$ Despite this, we observed that paramedics in the EMS system of Regina, a midsized Canadian city, were not consistently taking temperature readings. The digital thermometer (DT) in use did not appear to facilitate efficient temperature measurement because it was cumbersome to use and the paramedics questioned its accuracy. Because of this, the temporal artery thermometer (TAT) (Exergen, Watertown, MA) was investigated as a potential alternative measurement device. The TAT is a rapid, noninvasive measurement device that consists of an infrared scanner that detects emitted heat from the skin of the forehead and temporal region. ${ }^{5}$

In previous studies, the TAT has been compared to oral, axillary, rectal, bladder, and pulmonary artery catheter temperature measurements. ${ }^{2,3,6-10}$ The results indicate that the TAT has accuracy similar to that of axillary and oral measurements in the hospital setting, ${ }^{2,3}$ and it has been suggested that the TAT may serve as a suitable alternative for patients for whom invasive thermometry is contraindicated. ${ }^{6}$ TAT temperature measurements have also been found to correlate closely with pulmonary artery temperature measurement, with mean differences of less than $0.1^{\circ} \mathrm{C}\left(0.2^{\circ} \mathrm{F}\right) .^{3}$ Given the results of the TAT in critical care settings, these devices may be ideal for prehospital use, where a timely and noninvasive assessment of a patient's temperature by EMS personnel is required. To our knowledge, there has been no previous research of the TAT in the prehospital setting.

The primary objective of this study was to assess the performance of the TAT in the prehospital environment.

\section{METHODS}

\section{Study design}

A prospective, observational, mixed measures study design was used.

\section{Setting}

This study took place in the EMS system of Regina and compared the TAT to the DT currently used inambulance and then to the DT used in the emergency department of Regina General Hospital (the local receiving hospital). The temperature measurements were taken in the prehospital setting, either at the scene or in the ambulance, over two time periods: 31 days in October in mild weather (mean temperature $=7.2^{\circ} \mathrm{C}$ $\left[44.9^{\circ} \mathrm{F}\right]$; minimum $=-13.9^{\circ} \mathrm{C}\left[6.9^{\circ} \mathrm{F}\right]$; maximum $=$ $\left.25.8^{\circ} \mathrm{C}\left[78.4^{\circ} \mathrm{F}\right]\right)$ and 28 days in February in cold weather (mean temperature $=-14.3^{\circ} \mathrm{C}\left[6.2^{\circ} \mathrm{F}\right]$; minimum $=-32^{\circ} \mathrm{C}\left[-25.6^{\circ} \mathrm{F}\right]$; maximum $\left.=1.7^{\circ} \mathrm{C}\left[35^{\circ} \mathrm{F}\right]\right)$. The ambient (outside) temperature was recorded at the time the TAT temperatures were obtained.

\section{Selection of participants}

Patients who received transportation and/or medical treatment by EMS personnel and had temperatures obtained between October 2008 and February 2009 were eligible for inclusion. In the study region, prehospital temperature readings are a requirement for the EMS department, and only patients for whom temperature measurement was not appropriate (i.e., patients whose facial skin was obstructed, patients who were diaphoretic, and patients experiencing certain types of seizures) were excluded from the study. The average number of EMS calls in the study region is about 1,000 per month; therefore, the population from which the study sample was derived was approximately 2,000. The study was approved by the Research Ethics Board of Regina Qu'Appelle Health Region. No informed consent was required because temperature measurement is routinely performed by EMS personnel.

\section{Method of measurement}

Participant temperature readings were obtained by the Exergen TAT (TAT 5000), which costs over $\$ 300$ $\mathrm{CDN}$, and were compared to the DT currently in prehospital use in the study location (Accuflex Pro Digital Thermometer 016-638, Physio Logic, Montreal, QC), which is a small single-patient 
thermometer that costs less than $\$ 10 \mathrm{CDN}$. The TAT was also compared to the digital thermometer used in the local emergency department (Welch Allyn SureTemp Plus 690, Skaneateles Falls, NY), an institutional thermometer that costs over \$200 CDN. Previous research has compared this thermometer to a gold standard 3-minute aquisition temperature measurement, and no significant differences were found. ${ }^{11}$

\section{Data collection}

\section{Prehospital}

Participants had their prehospital temperature taken either at the scene or in the ambulance with both the DT (either orally or axillary) and the TAT during two 1-month trial periods. The trial periods were chosen to provide a month of mild weather (October; mean = $\left.7.2^{\circ} \mathrm{C}\left[44.9^{\circ} \mathrm{F}\right]\right)$ and a month of cold weather (February; mean $\left.=-14.3^{\circ} \mathrm{C}\left[6.2^{\circ} \mathrm{F}\right]\right)$. At the end of the trial periods, paramedics who used the TAT answered questions regarding the ease of use and general satisfaction with the thermometer.

\section{Emergency department}

Following the two periods of prehospital data collection, a chart review was conducted on a random sample of patients from the two trial periods to compare the TAT temperature reading to the hospital DT temperature reading when patients arrived at the emergency department. A random sampling technique was used (SPSS random sample of cases procedure).

\section{Outcomes}

The goals of this investigation were to answer the following questions: 1) How comparable are prehospital TAT temperature readings to prehospital DT readings? 2) How comparable are prehospital TAT readings to the DT readings in the emergency department? 3) Is any difference between temperature readings affected by any of the following extraneous factors: patient weight, sex, or age; diagnosis; perspiration; antipyretic drugs; or treatment? 4) Does cold weather affect the performance of the TAT? 5) How satisfied are the paramedics with the TAT?

\section{Data analysis}

Pearson correlation was used to evaluate the relationship between the various temperature measurement methods. As correlation does not indicate agreement between assessment devices, a Bland-Altman analysis was also performed. ${ }^{7}$ Acceptable agreement was deemed to be a difference of no more than $1.0^{\circ} \mathrm{C}\left(1.8^{\circ} \mathrm{F}\right)$, based on previous research suggesting that this degree of accuracy is clinically acceptable. ${ }^{8-10}$ Analyses of the factors' potential influence on temperature measurement were performed using $t$-tests or Pearson correlations where appropriate. All statistical analyses were performed using SPSS Statistics 17.0 (SPSS Inc, Chicago, IL) and MedCalc (MedCalc Software, Mariakerke, Belgium), and no power calculations or adjustments for multiple comparisons were performed.

\section{RESULTS}

\section{TAT compared to the in-ambulance DT}

\section{Demographics}

A total of 867 patients had prehospital temperatures obtained during the study period; 49 were excluded due to missing information, for a total of 818 cases analyzed. Seventy-nine percent (645 cases) of the digital temperatures were oral and 21\% (173 cases) were axillary. As the DT was used to take both oral and axillary temperature measurements, an independent samples $t$-test was performed to ensure that any difference in temperature measurement between the devices was not related to the method used to take the digital temperature (axillary or oral). This test was not significant $(t=-1.6, p>0.05)$, indicating that the temperature differences between devices was independent of the method (axillary or oral). Table 1 provides prehospital demographic information.

\section{Comparison of TAT and prehospital DT}

The correlation between the TAT and the prehospital DT measurements was positive and moderate (Pearson

\begin{tabular}{|c|c|}
\hline Variable $(n=818)$ & Mean (SD), $n(\%)$, or ratio \\
\hline Age (yr) & $61(25)$ \\
\hline Body mass index & $25.3(7.5)$ \\
\hline Sex (male/female) & $374 / 441$ \\
\hline Ambient temperature $\left({ }^{\circ} \mathrm{C}\right)$ & $-1.0(12.3)$ \\
\hline Mean temperature (TAT/DT) & $36.9(0.8) / 35.8(1.1)$ \\
\hline Sweating & $24(3 \%)$ \\
\hline Antipyretic therapy & $38(5 \%)$ \\
\hline Vasopressor therapy & $7(1 \%)$ \\
\hline
\end{tabular}


$r=0.42, p<0.001)$. A Bland-Altman plot of the mean difference between the temperatures measured (TAT DT) and the mean of the two measurements combined $($ TAT + DT) $/ 2$ was graphed (Figure 1). The amount of agreement, which is summarized by the bias (mean difference and the standard deviation), was $1.1^{\circ} \mathrm{C}\left(2.0^{\circ} \mathrm{F}\right)$ $(\mathrm{SD}=1.1)$. The Bland-Altman plot indicates that the confidence interval (CI) of agreement ranged from $-1.1^{\circ} \mathrm{C}\left(-2.0^{\circ} \mathrm{F}\right)$ to $3.2^{\circ} \mathrm{C}\left(5.8^{\circ} \mathrm{F}\right)$, exceeding our predefined limits of clinical acceptability of $1^{\circ} \mathrm{C}$ $\left(1.8^{\circ} \mathrm{F}\right)$. Fifty-seven percent of the mean differences between the temperature devices exceeded the $\pm 1{ }^{\circ} \mathrm{C}$ $\left(1.8^{\circ} \mathrm{F}\right)$ threshold; thus, there was poor agreement between the two temperature measurement devices.

The CI of the mean difference illustrates the magnitude of the systematic difference, and as the line of equity (the point at which there is no difference between readings) is not within this CI, there is a significant systematic difference between the two temperature devices. The DT readings were systematically lower than the TAT temperature readings.

\section{TAT compared to the emergency department digital thermometer}

\section{Demographics}

There were 150 cases randomly selected from the overall database of 845 for the chart audit comparison of the TAT and the emergency department digital thermometer (ED-DT). Incomplete information such as missing temperature, unrecorded or inaccurate date or time the temperature was taken, or a time difference $>2$ hours between recordings led to 81 charts being excluded from further analysis. Consequently, 69 cases were used to compare the TAT temperatures to those taken with the ED-DT. Demographic information on the chart audit sample is provided in Table 2. As the sample size was small, the variables obtained from chart audit sample were compared to the overall sample and no significant differences were found, suggesting the chart audit sample was representative of the larger study population.

There was a time delay between the prehospital and emergency department temperature measurements (mean delay of 28 minutes and 20 seconds). This delay arose due to the amount of time it took for the ambulance to arrive at the hospital and because emergency department temperature measurements were completed in the patient's room. To determine whether the time delay affected the results, the time difference between the temperature measurements (inambulance and emergency department) was plotted against the difference in the temperature reading, and no upward or downward trend was observed, suggesting that the time delay did not increase the difference between temperature measurements.

\section{Comparison of TAT and ED-DT}

A positive correlation was found between the TAT and the ED-DT (Pearson $r=0.60, p<0.001$ ). The

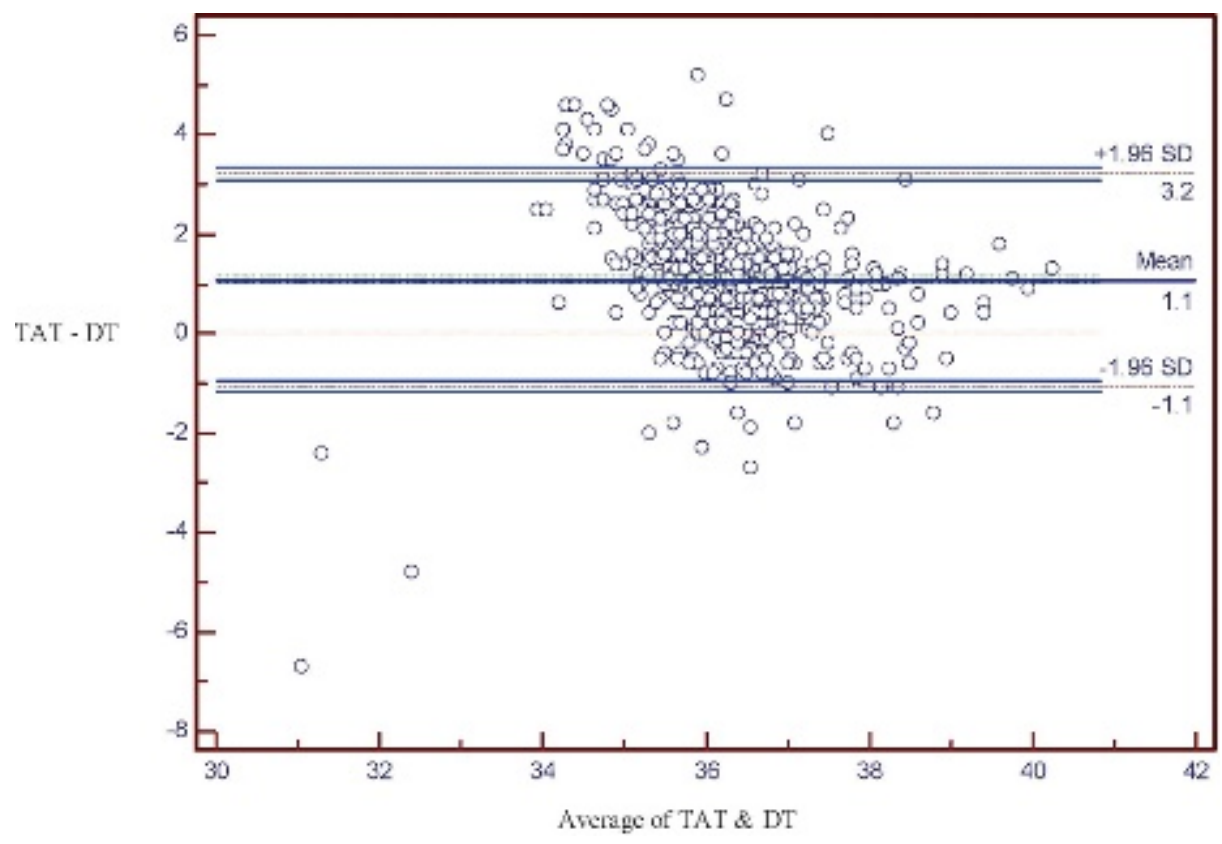

Figure 1. Bland-Altman plot of temporal artery thermometer (TAT) and prehospital digital thermometer (DT) mean measurement differences $(n=818)$. 


\begin{tabular}{|c|c|}
\hline Variable $(n=69)$ & Mean (SD), $\mathrm{r} n(\%)$, or ratio \\
\hline Age (yr) & $64(26)$ \\
\hline Body mass index & $24.4(5.5)$ \\
\hline Sex (male/female) & $34 / 34$ \\
\hline Ambient temperature $\left({ }^{\circ} \mathrm{C}\right)$ & $-0.2(10.7)$ \\
\hline Mean temperature (TAT/ED-DT) & $36.8(0.7) / 36.7(0.6)$ \\
\hline Sweating & $2(3 \%)$ \\
\hline Antipyretic drugs & $3(4 \%)$ \\
\hline Vasopressor therapy & $1(1 \%)$ \\
\hline
\end{tabular}

Bland-Altman plot (Figure 2) indicates that the difference between the TAT and the ED-DT (mean $\left.=0.11^{\circ} \mathrm{C}\left[0.2^{\circ} \mathrm{F}\right] ; \mathrm{SD}=0.60\right)$, was within the acceptable $1^{\circ} \mathrm{C}\left(1.8^{\circ} \mathrm{F}\right)$ difference range. The $\mathrm{CI}$ of agreement ranged from $-1.1\left(2.0^{\circ} \mathrm{F}\right)$ to $1.3^{\circ} \mathrm{C}\left(2.3^{\circ} \mathrm{F}\right)$, slightly exceeding $1^{\circ} \mathrm{C}\left(1.8^{\circ} \mathrm{F}\right)$; however, $93 \%$ of the mean differences between the temperature devices were within the $\pm 1^{\circ} \mathrm{C}\left(1.8^{\circ} \mathrm{F}\right)$ threshold. This result indicates good agreement exists between the two measurement devices, an interpretation further supported by the fact that no systematic differences were found between the measurement devices.

\section{Comparison of prehospital DT to the ED-DT}

To control for potential differences between the temperature devices, the prehospital DT and the ED-DT were compared. There was a correlation between the two temperature measurements devices $(r=0.56, p<0.001)$. However, the Bland-Altman analyses indicated a lack of agreement (Figure 3), similar to that of the TAT and the prehospital DT. The bias of the in-ambulance DT and the ED-DT was $1.2^{\circ} \mathrm{C}\left(2.2^{\circ} \mathrm{F} ; \mathrm{SD}=1.1\right)$ and therefore not within the acceptable $1^{\circ} \mathrm{C}\left(1.8^{\circ} \mathrm{F}\right)$ range. The plot indicates that the $\mathrm{CI}$ of agreement ranged from $-1.0^{\circ} \mathrm{C}\left(-1.8^{\circ} \mathrm{F}\right)$ to $3.4^{\circ} \mathrm{C}\left(6.1^{\circ} \mathrm{F}\right)$ and $54 \%$ of the mean differences exceeded the $\pm 1^{\circ} \mathrm{C}\left(1.8^{\circ} \mathrm{F}\right)$ threshold. The plot also shows that the line of equity is not within the CI of the mean difference, indicating that the prehospital DT readings were systematically lower than the EDDT temperature readings. Therefore, the prehospital DT was systematically lower than both the TAT and the ED-DT. A comparison of all three thermometers is provided in Table 3 .

\section{Extraneous factors}

Age was the only extraneous factor found to be correlated to the difference between temperature reading of the prehospital DT and the TAT $(r=$ $0.13, p<0.001)$; however, given the low correlation, the impact of age on the readings is minimal.

\section{Effects of weather on TAT}

In 30 separate instances, paramedics reported an error code on the TAT. All 30 error readings occurred

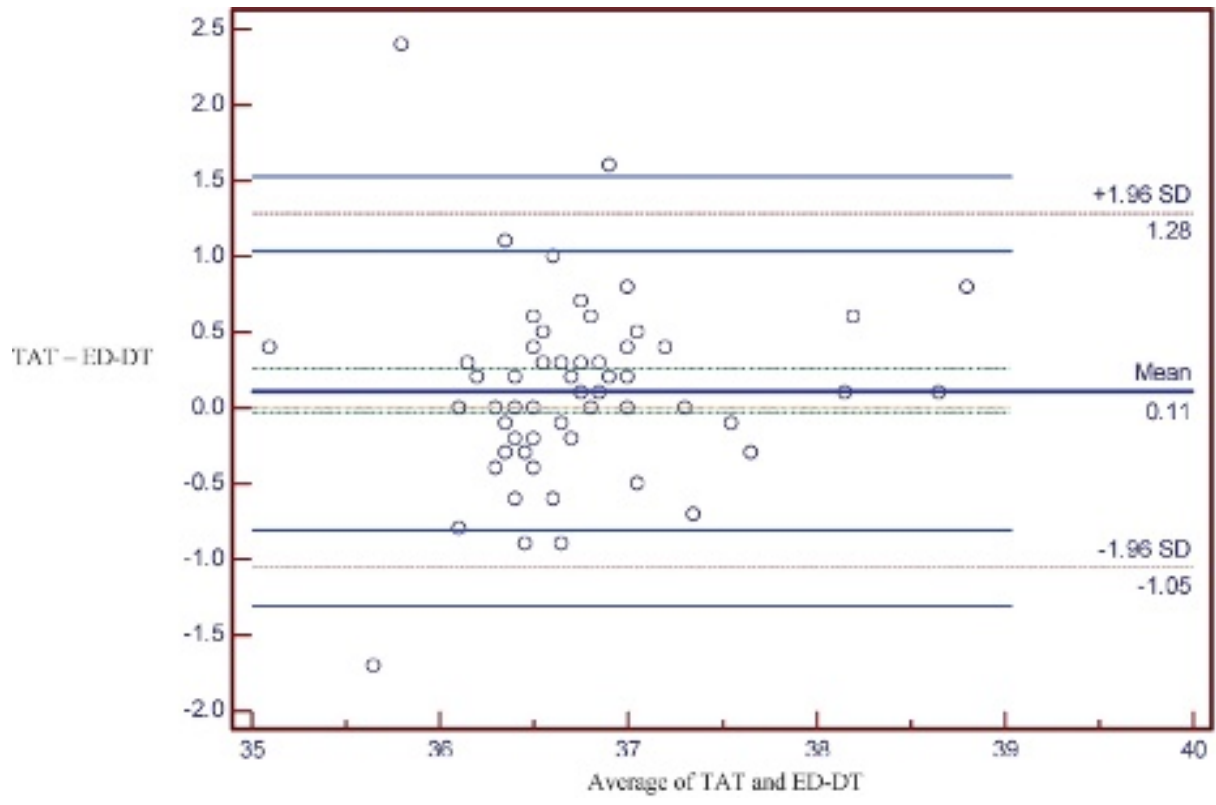

Figure 2. Bland-Altman plot for the temporal artery thermometer (TAT) and the emergency department digital thermometer (ED-DT) $(n=69)$. 


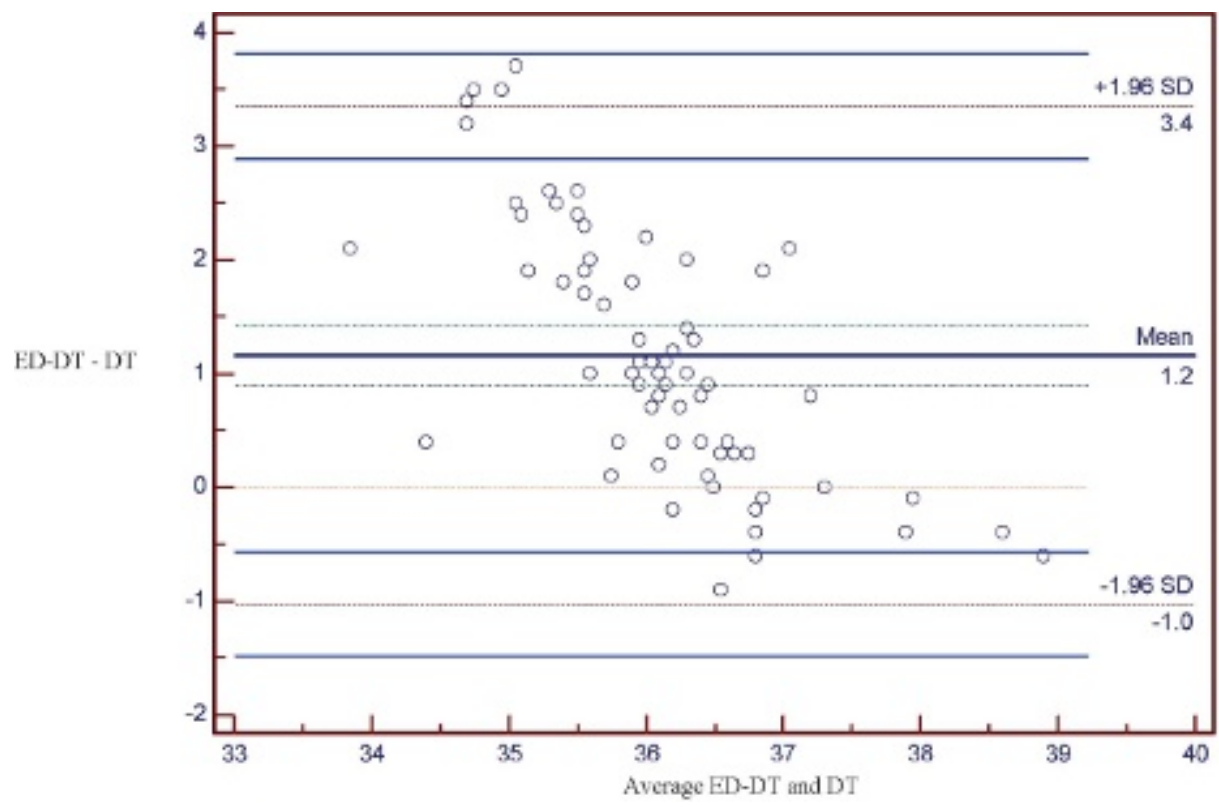

Figure 3. Bland-Altman plot for the emergency department digital thermometer (ED-DT) and the prehospital digital thermometer (DT) $(n=69)$. during cold ambient outdoor temperatures with an average temperature of $-15.2^{\circ} \mathrm{C}\left(4.6^{\circ} \mathrm{F}\right.$; $\left.\mathrm{SD}=7.8\right)$. Error readings were significantly more likely to occur when external temperatures were cooler $(t=-6.68, p$ $<0.01)$. Although sometimes the thermometer failed to produce a reading in cold temperatures, it should be noted that this did not affect the reading when it was produced after the error code was cleared. One solution suggested by paramedics was to ensure the TAT was stored in a warm place (e.g., the cabin of the EMS vehicle).

\section{Paramedic satisfaction with the TAT}

Sixty-three paramedics answered questions regarding the TAT. Ninety-seven percent thought that the TAT was easier to use than the digital device currently used, and $98 \%$ indicated that it saved time. Ninety-four percent of paramedics surveyed were satisfied with the TAT.

\section{DISCUSSION}

\section{Clinical applicability}

This study was not designed to determine any superiority of temperature devices. Rather, we sought to determine whether the TAT is useful in the prehospital setting. The prehospital DT did not have clinically acceptable agreement with either the TAT or the ED-DT and had systematically lower temperature readings than both. The temperatures taken with the TAT had good agreement and were significantly correlated to the ED-DT temperature measurements. This agreement suggests that the TAT performed as accurately as the primary temperature measurement tool used in the emergency department, a finding similar to the results of previous studies comparing the TAT to oral and axillary thermometers. ${ }^{2,3}$ The TAT was not affected by extraneous factors, and although the TAT produced error codes in cold weather, this problem was easily solved by storing the TAT in the

\begin{tabular}{|c|c|c|c|}
\hline & $n$ & Mean difference (SD) $\left({ }^{\circ} \mathrm{C}\right)$ & Limits of agreement $\left({ }^{\circ} \mathrm{C}\right)$ \\
\hline TAT and prehospital DT & 818 & $1.1(1.1)$ & -1.1 to 3.2 \\
\hline TAT and ED-DT & 69 & $0.1(0.6)$ & -1.1 to 1.0 \\
\hline Prehospital DT and ED-DT & 69 & $1.2(1.1)$ & -1.0 to 3.4 \\
\hline
\end{tabular}


cabin of the ambulance. The TAT was well liked and perceived to be more accurate than the current inambulance DT. Our findings suggest that the TAT is useful in the prehospital setting.

\section{Limitations}

A major limitation of this study is the small sample from the chart audit, which arose due to the high proportion of exclusions. This affected our ability to draw conclusions based on the comparisons between the prehospital temperature measurements and the emergency department temperature measurements and increased the chance of a false negative conclusion. However, even with the small sample size for the comparisons, the TAT had good agreement and was significantly correlated to the ED-DT. The chart audit drew attention to the unrelated issue of the accuracy and consistency of chart recordings in health care, and in hindsight, a chart audit of a larger random sample would have been preferable.

A second limitation of this study is that the temperature measurements taken in the hospital had a time delay from those taken in the ambulance. This is a problem because the more time that passes, the more chance there is for a patient's temperature to change. However, from our results, it appeared that this time delay did not cause increased disagreement in the temperature measurements. If this study were to be replicated, it would be important to ensure that the time delay between in-ambulance and emergency department temperature measures is lessened.

\section{CONCLUSION}

The TAT appears to be a suitable alternative to DTs currently used in many EMS systems. The paramedics involved in this study liked the TAT better than the in-ambulance DT and believed it to be more accurate. Future research is needed to investigate the correlation between TAT temperature readings and those in the emergency department. Of note, the results of this study brought about change in practice within the study location EMS system, with the TAT replacing DTs in ambulances.

Competing interests: None declared.

\section{REFERENCES}

1. Saskatchewan Ministry of Health. Saskatchewan emergency treatment protocol manual. Ministry of Health guidelines for the treatment of emergent and nonemergent patients in the pre-hospital setting. Available at: http://www.health.gov.sk.ca/adx/aspx/adxGetMedia. aspx? DocID $=2331,94,88$, Documents $\&$ MediaID $=2284 \&$ Filename $=$ ems-protocols.pdf (accessed April, 2008).

2. Hebbar K, Fortenberry JD, Rogers K, et al. Comparison of temporal artery thermometer to standard temperature measurements in pediatric intensive care unit patients. Pediatr Crit Care Med 2005;6:557-61, doi:10.1097/01. PCC.0000163671.69197.16.

3. Lawson L, Bridges EJ, Ballou I, et al. Accuracy and precision of non-invasive temperature measreument in adult intensive care patients. Am 7 Crit Care 2007;16:485-96.

4. Clumpner M, Mobley J. Raising the dead. Prehospital hypothermia for cardiac arrest victims may improve neurological outcome and survival to discharge. EMS Mag 2008;37:52-60

5. Exergen Corporation. Frequently asked questions. Available at: http://www.exergen.com/medical/TAT/tatfaq.html (accessed April 28, 2010).

6. Myny D, De Waele J, Defloor T, et al. Temporal scanner thermometry: a new method of core temperature estimation in ICU patients. Scott Med 7 2005;50:15-8.

7. Bland JM, Altman DG. Statistical methods for assessing agreement between two methods of clinical measurement. Lancet 1986;1:307-10, doi:10.1016/S0140-6736(86)90837-8.

8. Fetzer SJ, Lawerence A. Tympanic membrane versus temporal artery temperatures of adult perianesthesia patients. 7 Perianesth Nurs 2008;23:230-6, doi:10.1016/j. jopan.2008.01.010.

9. Woodrow P, May V, Buras-Rees S, et al. Comparing notouch and tympanic thermometer temperature recordings. Br 7 Nurs 2006;15:1010-6.

10. Greenes DS, Fleisher GR. Accuracy of a non-invasive temporal artery thermometer for use in infants. Arch Pediatr Adolesc Med 2001;155:376-81.

11. Welch Allyn Inc. Clinical accuracy of a rapid thermistor thermometer. The Welch Allyn SureTemp ${ }^{\circledR}$ clinical thermometer. Available at: http://www.welchallyn.com/documents/ Thermometry/Electronic\%20Thermometry/SureTemp\% 20692/Clin_Acc_Stud_Rapid_Therm_OLC.pdf (accessed January 4, 2011). 